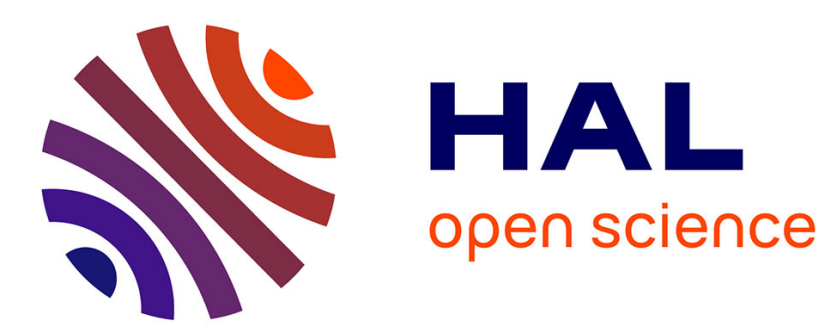

\title{
Optimal Cost Design of Flow Lines with Reconfigurable Machines for Batch Production
}

Olga Battaïa, Alexandre Dolgui, Nikolai Guschinsky

\section{To cite this version:}

Olga Battaïa, Alexandre Dolgui, Nikolai Guschinsky. Optimal Cost Design of Flow Lines with Reconfigurable Machines for Batch Production. International Journal of Production Research, 2020, 58 (10), pp.2937-2952. 10.1080/00207543.2020.1716092 . hal-02568324

\section{HAL Id: hal-02568324 \\ https://hal.science/hal-02568324}

Submitted on 8 May 2020

HAL is a multi-disciplinary open access archive for the deposit and dissemination of scientific research documents, whether they are published or not. The documents may come from teaching and research institutions in France or abroad, or from public or private research centers.
L'archive ouverte pluridisciplinaire HAL, est destinée au dépôt et à la diffusion de documents scientifiques de niveau recherche, publiés ou non, émanant des établissements d'enseignement et de recherche français ou étrangers, des laboratoires publics ou privés. 
Paper accepted for publication in IJPR

https://www.tandfonline.com/doi/full/10.1080/00207543.2020.1716092

\title{
Optimal Cost Design of Flow Lines with Reconfigurable Machines for Batch Production
}

\author{
Olga Battaïa ${ }^{1}$, Alexandre Dolgui ${ }^{2}$, Nikolai Guschinsky $^{3}$ \\ ${ }^{1}$ ISAE-Supaero, Toulouse, France \\ ${ }^{2}$ IMT Atlantique, LS2N- CNRS, Nantes, France \\ ${ }^{3}$ United Institute of Informatics Problems, National Academy of Sciences, Minsk, Belarus
}

\begin{abstract}
:
Modular reconfigurable machines offer the possibility to efficiently produce a family of different parts. This paper formalizes a cost optimization problem for flow lines equipped with reconfigurable machines which carry turrets, machining modules and single spindles. The proposed models take into account constraints related to: i) design of machining modules, turrets, and machines, ii) part locations, and iii) precedence relations among operations. The goal is to minimize equipment cost while reaching a given output and satisfying all the constraints. A Mixed Integer Program (MIP) is developed for the considered optimization problem. The approach is validated through an industrial case study and extensive numerical experiments.
\end{abstract}

Keywords: Reconfigurable manufacturing systems, Reconfigurable machine-tools, Manufacturing lines, Batch processing, Line design and balancing, Cost minimization, Optimization.

\section{Introduction}

Batch production is often used in low-volume diversified manufacturing context which is gaining more and more importance due to the major trend of product customization (Liao et al., 2017, Buer et al., 2018, $\mathrm{Xu}$ et al., 2018, Yin et al., 2018, Dolgui et al., 2019). A batch is a set of different parts that are manufactured together, it means that all the parts of the same batch follow the same manufacturing path, but each part receives its own operations. In reconfigurable manufacturing systems, operating modules of machines can be adapted for each batch. However, it is preferably to not use equipment reconfigurations for the parts of the same batch. Therefore, the batches are constituted in the way that the processing of the parts within the same batch will not require any equipment reconfiguration. The reconfiguration is only realized if needed between two different batches. In this paper, we consider a design problem for a reconfigurable manufacturing system for batch production. The design objective is to decide which modules will be used for each batch of products at which machine as well as which will be the general layout of the manufacturing system.

The considered manufacturing system may consist of several reconfigurable machines composed of different machining modules (spindle heads). A subset of machining modules is used for manufacturing each batch of parts. The decision on the modules to be used in the system and the number of machines has 
to be made taking into account the parts to be produced and their quantity (size of each batch). Machining modules of a machine can be activated simultaneously or sequentially when applied to the same part. Simultaneous activation is realized for modules machined different accessible sides of the part. Sequential application is realized by the use of turrets which can carry several machining modules. In such a configuration, each part can be machined by at most 4 parallel modules corresponding to accessible sides of the machined part (two examples of such machines are shown in Fig. 1 and Fig. 2).

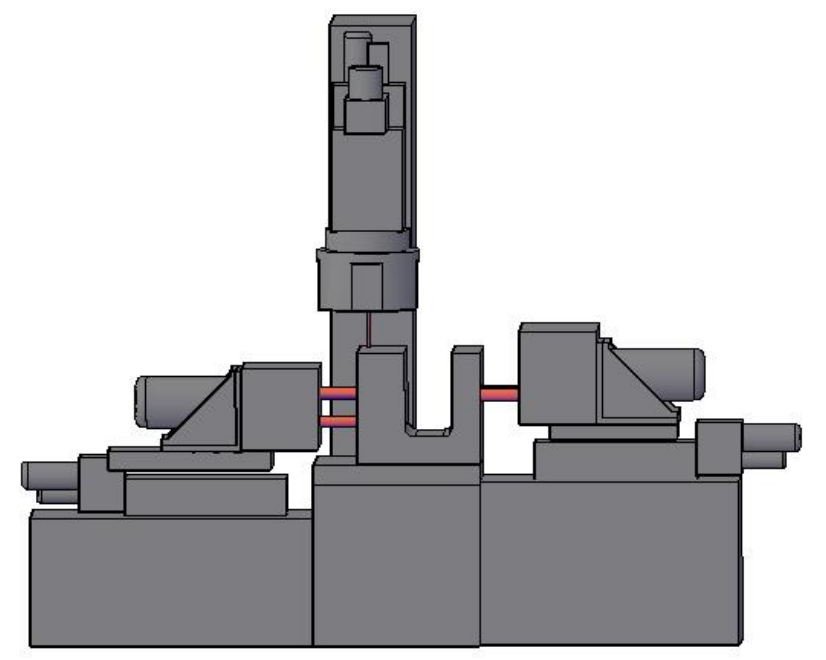

Fig. 1. A machine with one vertical turret and 2 horizontal modules

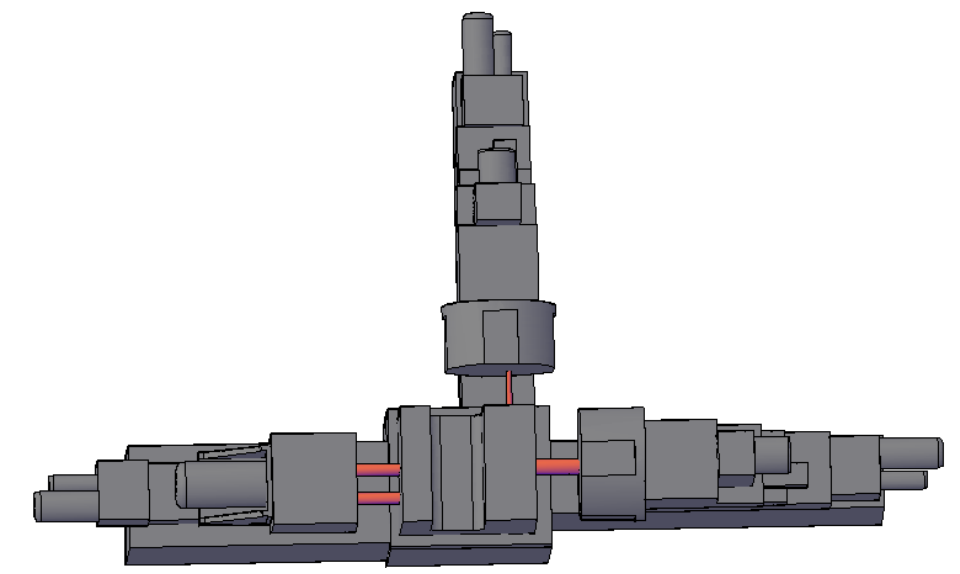

Fig. 2. A machine with two horizontal turrets and one horizontal module

The design problem considered in this paper concerns the choice of number of reconfigurable machines as well as the equipment to be installed on in terms of turrets and machining modules in order to machine a given number of batches. Since the location and machining axe and direction has to be decided for each machining module, the design solution defines also the orientations of each part on each machine, as well as cutting modes for each machining module.

The rest of the paper is organized as follows. Section 2 analyses the state of the art in the field. Section 3 provides a formal problem statement and Section 4 presents a mathematical model for it. A case study is described in Section 5. Finally, Section 6 concludes the study and suggests research perspectives. 


\section{Literature review}

The research on reconfigurable manufacturing systems (RMS) introduced by Koren et al. 20 years ago (Koren et al. 1999) actually attracts a growing number of academic and industrial studies (Bortolini et al., 2018). This is due to the fact that RMS offer a novel effective manufacturing paradigm for nowadays production challenges characterized by an increasing variety of customized, high-quality products. A large number of publications dedicated to the research on RMS can be found in the literature. They provide multiple insights on the research perspectives in the field: on theoretical and practical challenges in the design of RMS (Rosio and Safsten, 2013), on measures of reconfigurability (Farid, 2014), on the use of artificial intelligence for the design of RMS (Renzi et al., 2014), on the adaptation of RMS for industrial assembly (Huettemann et al., 2015), on reconfigurable manufacturing on multiple levels (Andresen et al., 2015), on prerequisites and barriers for the development of RMS (Andresen et al., 2016), on the current design methods for RMS (Andersen et al., 2017). In particular, three recent surveys give a comprehensive view of challenges and research trends (Singh et al., 2017, Bortolini et al., 2018, Brahimi et al., 2019) where the interested reader will find a historical perspective of RMS development, detailed discussions on the topics attracting the major streams of research and future trends. Due to the availability of these complete bibliographical studies in the literature, we focus our literature analysis on the work that is the closest to our research question.

As for traditional manufacturing systems, the research on RMS concerns both the design and operation levels. Since in this study, a design problem is considered, the literature review is focused on the design level where a configuration of the system has to be defined and an equipment selection has to be made. These decisions however are usually closely related to the decisions on operation assignments to manufacturing modules and machines (Koren and Shpitalni, 2010).

One of the first studies on the design of RMS with the objective to optimize the investment cost can be found in Youssef and ElMaraghy (2006). This study has been consequently extended by considering a reconfiguration smoothness metric (Youssef and ElMaraghy, 2007) and machine availability (Youssef and ElMaraghy, 2008). Dou et al. $(2007,2010)$ studied reconfigurable flow lines with the objective to optimize the total investment cost for single- and multi-part flow lines, respectively. This research was further extended to a configuration generation problem where both the total cost and the total tardiness were minimized (Dou et al., 2016). Ashraf and Hasan (2018) considered the problem of optimal configuration selection of reconfigurable machine tools (RMT) for a reconfigurable serial flow line. These studies are close to our work, however, our design problem needs a more sophisticated mathematical model since the configuration of each machining module and the corresponding cutting 
tools have to be defined according to the results of the optimization and not taken from a catalogue. As a consequence, more refined mathematical models are developed in the present study. In our previous work (Battaïa et al., 2017), we studied a close problem for rotary machining systems and here we extend the obtained mathematical model to a more general machining system layout.

The estimation of the total cost of RMS over planning horizon has been investigated in several studies. The optimization of the cost for scalability of RMS systems, in other words, their ability to be adapted to the scale of production volume was investigated by Son et al. (2001), Spicer et al. (2005), Wang and Koren (2012), and Koren et al., (2016). Saxena and Jain (2012) explored the structure of the cost of RMS including equipment investment, reconfiguration cost, operating cost, maintenance cost and residual marginal value over time. Xiaobo et al. (2000 a,b, $2001 \mathrm{a}, \mathrm{b})$ used stochastic optimization to maximize the average expected profit for a designed RMS. Production planning of RMS with stochastic demands was investigated by Abbasi and Houshmand (2009, 2011). The problem of RMS configuration design is also addressed in Moghaddam et al. (2017), where the demand of a single product varies throughout its production life cycle, and the system configuration can change to satisfy the required demand with a minimum cost. The problem of selecting the optimal machining parameters for all operations of a batch processing line that minimize the total batch production cost while ensuring the required line throughput was studied by Dolgui et al. (2019).

In terms of multi-objective optimization, the cost is often regarded jointly with the total completion time, e.g. Bensmaine et al. (2013) and Haddou-Benderbal et al. (2017). Goyal et al. (2012, 2013) introduced a multi-objective model for the optimal machine assignment for a single part flow line with the objective to find a trade-off between the cost and the responsiveness of the RMS. The bi-objective model by Dou et al. (2016) was developed both for design and scheduling levels in order to minimize the investment and reconfiguration costs as well as total tardiness. The choice of single or multi-objective optimization depends on the criteria used in particular decision context. In our study, the industrial designers are principally interested by the criterion of the total investment cost while the production time is considered as a hard constraint.

The description of the optimization problem addressed in this paper is given in the next section. The aim of the study is not on the technology level but to facilitate the decision making process related to the preliminary design (combinatorial design) of RMS. In our study, we consider the stage of the design of RMS for a planning horizon with a known set of parts, therefore, the designed system includes all equipment required to process all known parts, it means that the reconfiguration "cost" is included in the investment cost, if the same equipment can be used for different parts it will be preferred in the design solution. The problem of reconfiguration for "unknown" parts is not considered in the present study. This optimization problem for batch production design is novel and not been addressed in the literature yet. 
Moreover, the model we develop does not only help to solve this specific problem, but also offers new ideas for modelling and solving other similar optimization issues.

\section{Problem statement}

The considered design problem consists in defining the number of reconfigurable machines $m$ and their configurations in order to produce $d_{0}$ types of parts. The parts are grouped in $\aleph$ batches with required output $O_{v}$ (where $v$ is the number of batch , $\left.v=1,2, \ldots, \aleph\right)$. Batches and parts in each batch are processed sequentially. Parts of $v^{\text {th }}$ batch are loaded in sequence $\pi_{v}=\left(\pi_{v 1}, \pi_{v 2}, \ldots, \pi_{v \mu_{v}}\right)$ where $\pi_{v j} \in\left\{1,2, \ldots, d_{0}\right\}$, $j=1,2, \ldots, \mu_{v}$ where $\mu_{v}$ is the number of parts processed in a sequence in batch $v=O_{v}$ Using sequences $\pi_{v}$ we can define, in one-to-one manner, function $\pi_{v}(i, k), i=1, \ldots, O_{v} \mu_{v}+m-1$, of part number on $k^{\text {th }}$ machine after $i$ movements of the conveyer, $\pi_{v}(i, k) \in\left\{0,1,2, \ldots, d_{0}\right\}\left(\pi_{v}(i, k)=0\right.$ means that no part is processed on $k^{\text {th }}$ machine).

Figures 3 to 5 in Section 5 show an example of batch of three different parts.

Let us recall the introduced indexes for further presentation of parameters and decision variables:

- Index for reconfigurable machines $k=1, \ldots, m$, where $m$ is the number of machines.

- Index for parts: $d \in D=\left\{1,2, \ldots, d_{0}\right\}$, where $d_{0}$ is the number of types of parts.

- Index for batches : $\mathrm{v}=1,2, \ldots, \aleph$, where $\aleph$ is the number of batches to be produced.

- Index for the positions of parts in sequence of each batch: $\pi_{v}=\left(\pi_{v 1}, \pi_{v 2}, \ldots, \pi_{v \mu_{v}}\right)$ where $\pi_{v j} \in\left\{1,2, \ldots, d_{0}\right\}, j=1,2, \ldots, \mu_{v}$ and $\mu_{v}$ is the number of parts processed in a sequence in batch $v=$ Ov.

Let $\mathbf{N}^{d}$ be the set of machining operations needed for machining of elements of $d^{\text {th }}$ part, $d \in D=\left\{1,2, \ldots, d_{0}\right\}$ located on its $n_{d}$ sides and $N_{s}^{d}, s=1,2, \ldots, n_{d}$, is a subset of operations for machining of elements of $s^{\text {th }}$ side of the part $d$. The part $d$ can be located at a machine in different orientations $\mathbf{H}(d)$ but elements of no more than one side can be processed by a machining module. Machining modules can be of 4 types: type $j=1$ (from above), $j=2$ (from the left), $j=3$ (from behind), $j=4$ (from the right) and no more than 3 types of machining modules can be installed at each machine. $\mathbf{H}(d)$ can be represented by a matrix of dimensions $r_{d} \mathrm{x} n_{d}$ where $h_{r s}(d)$ is equal $j, j=0,1,2,3,4$, if the operations of $N_{s}^{d}$ can be processed by machining modules of type $j(j=0$ means that processing is not possible). 
Let $\mathbf{N}$ be the set of all operations required for completing all considered parts, $\mathbf{N}=\bigcup_{d=1}^{d_{0}} \mathbf{N}^{d}$. Any operation $p \in \mathbf{N}$ is characterized by the following parameters: the length $\lambda(p)$ of the working stroke for operation $p$, the range $\left[\gamma_{1}(p), \gamma_{2}(p)\right]$ of feasible values of feed rate defining cutting speed, and the set $J(p)$ of types of possible machining modules for execution of operation $p$.

The considered optimization problem is to determine:

- the number $m$ of machines;

- the orientation $H_{d k}$ of part $d \in D$ at machine $k, k=1, \ldots, m$;

- the number $b_{k j}$ of machining modules of type $j, j=1, \ldots, 4$, that are installed at machine $k, k=1, \ldots, m$;

- the set of machining operations $N_{d k j l}$ from $\mathbf{N}^{d}$, assigned to machining module $l$ of type $j$ at machine $k$, $d \in D, k=1, \ldots, m, j=1, \ldots, 4, l=1, \ldots, b_{k j}$;

- the feed rate $\Gamma_{d k j l} \in\left[\max \left\{\gamma_{1}(u) \mid u \in N_{d k j l}\right\}, \min \left\{\gamma_{2}(u) \mid u \in N_{d k j l}\right\}\right]$ for execution of operations from $N_{d k j l}, d \in D$, $k=1, \ldots, m, j=1, \ldots, 4, l=1, \ldots, b_{k j}$.

Let $P_{d k j}=\left(P_{d k j l}=\left(N_{d k j l}, \Gamma_{d k j l}\right) \mid l=1, \ldots, b_{k j}\right), P_{d k}=\left(P_{d k j} \mid j=1, \ldots, 4\right), P_{d}=\left(\left(P_{d k}, H_{d k}\right) \mid k=1, \ldots, m\right), P=\left(P_{d} \mid d \in D\right)$. $P$ is a design decision.

The execution time $t^{b}\left(P_{d k j l}\right)$ of operations from $N_{d k j l}$ with the feed rate $\Gamma_{d k j l} \in\left[\max \left\{\gamma_{1}(p) \mid p \in N_{d k j l}\right\}, \min \left\{\gamma_{2}(p) \mid p \in N_{d k j l}\right\}\right] \quad$ is $\quad$ equal $\quad$ to $\quad t^{b}\left(P_{d k j l}\right)=L\left(N_{d k j l}\right) / \Gamma_{d k j l}+\tau^{a}, \quad$ where $L\left(N_{d k j l}\right)=\max \left\{\lambda(p) \mid p \in N_{d k j l}\right\}$, and $\tau^{a}$ is an additional time for advance and disengagement of tools.

We assume that if the turret of type $j$ is installed at machine $k$ then the execution time of operations from $N_{d k j l}$ is equal to $t^{h}\left(P_{d k j}\right)=\tau^{g} b_{k j}+\sum_{l=1}^{b_{k j}} t^{b}\left(P_{d k j l}\right), j=1, \ldots, 4$, where $\tau^{g}$ is an additional time for one rotation of a turret. If the spindle head is installed, then $t^{h}\left(P_{d k j}\right)=t^{b}\left(P_{d k j l}\right), j=1, \ldots, 4$. If all $N_{d k j l}$ are empty then $t^{h}\left(P_{d k j}\right)=0$. If $b_{k j}=1$, then $t^{h}\left(P_{d k j}\right)=t^{b}\left(P_{d k j 1}\right)$.

The execution time $t^{p}\left(P_{d k}\right)$ is defined as $t^{p}\left(P_{d k}\right)=\tau^{r}+\max \left\{t^{h}\left(P_{d k j}\right) \mid j=1, \ldots, 4\right\}$, where $\tau^{r}$ is an additional time for part transportation and its location at a machine. Then the time $T_{v}(P)$ of execution of all corresponding operations for batch $v$ is defined as $T_{v}(P)=\sum_{i=1}^{O_{v} \mu_{v}+m-1} \max \left\{t^{p}\left(P_{\pi_{v}}(i, k) k\right) \mid k=1, \ldots, m\right\}$ and the time $T(P)$ for machining all the batches is equal to $\sum_{v=1}^{\aleph} T_{v}(P)$.

We assume that the given productivity is provided, if the total time $T(P)$ does not exceed the available time $T_{0}$. 
Let $C_{s m}, C_{t b}, C_{m m}, C_{s b}$, and $C_{s t}$ be the relative costs for one machine, one turret, one machining module of a turret, one spindle box, and one workhead with a single spindle, respectively. Then the cost $C\left(b_{k j}\right)$ for performing set of operations $N_{k j}$ by associated $b_{k j}$ machining modules can be assessed as follows:

$$
C\left(b_{k j}\right)=\left\{\begin{array}{c}
0 \text { if } b_{k j}=0, \\
C_{s t} \text { if } b_{k j}=1 \text { and }\left|N_{k j 1}\right|=1, \\
C_{s b} \text { if } b_{k j}=1 \text { and }\left|N_{k j 1}\right|>1, \\
C_{t b}+C_{m m} b_{k j} \text { if } b_{k j}>1
\end{array}\right.
$$

The machine cost $Q(P)$ is calculated as the total cost of all equipment used:

$$
Q(P)=C_{s m} m+\sum_{k=1}^{m} \sum_{j=1}^{4} C\left(b_{k j}\right)+\sum_{k=1}^{m-1} \sum_{d=1}^{d_{0}} C\left(H_{d k}, H_{d k+1}\right),
$$

where $C\left(H_{d k}, H_{d k+1}\right)$ is the cost incurred by changing orientation of part $d$ between stations $k$ and $k+1$ and $C\left(H_{d k}, H_{d k+1}\right)=0$ if $H_{d k}=H_{d k+1}$ and $C\left(H_{d k}, H_{d k+1}\right)=C_{r o}$, otherwise ( $C_{r o}$ is the relative cost for reorientation).

The design decision $P$ should satisfy the following constraints:

- precedence constraints which define time dependencies among operations;

- inclusion constraints which require to execute some pairs of operations from $\mathbf{N}$ at the same machine, by the same turret, by the same machining module or even by the same spindle;

- exclusion constraints which require to not assign some pairs of operations from $\mathbf{N}$ to the same machine, to the same turret, or to the same machining module;

- constraints on the maximal number $m_{0}$ of machines and on the maximal number $b_{0}$ of machining modules in a turret;

- constraints on feasible orientations of the part for processing each operation;

- the impossibility to perform operations from $N_{s}^{d}$ at one machine by machining modules of different types;

- productivity constraints to provide the required output (a time limit for total completion time).

Precedence constraints are modelled by a directed graph $G^{O R}=\left(\mathbf{N}, D^{O R}\right)$ : if an $\operatorname{arc}(p, q) \in D^{O R}$ then operation $p$ has to be executed before operation $q$. It should be noted that if such operations $p$ and $q$ belong to different sides of the part, then they cannot be executed at the same machine without violating the precedence constraint.

Inclusion constraints are represented by undirected graphs $G^{S P}=\left(\mathbf{N}, E^{S P}\right), G^{S T}=\left(\mathbf{N}, E^{S T}\right), G^{S M}=\left(\mathbf{N}, E^{S M}\right)$ and $G^{S S}=\left(\mathbf{N}, E^{S S}\right)$ : if there is an edge $(p, q) \in E^{S S}$ (or $(p, q) \in E^{S M}$, or $(p, q) \in E^{S T}$, or $\left.(p, q) \in E^{S P}\right)$, then operations $p$ and $q$ must be executed by the same spindle (the same machining module, turret, at the same machine, respectively). 
Exclusion constraints are represented by undirected graphs $G^{D M}=\left(\mathbf{N}, E^{D M}\right), G^{D T}=\left(\mathbf{N}, E^{D T}\right)$, and $G^{D P}=\left(\mathbf{N}, E^{D P}\right)$. If there is an edge $(p, q) \in E^{D M}\left(\right.$ or $\left.(p, q) \in E^{D T}\right)$, or $\left.\left.(p, q) \in E^{D P}\right)\right)$, then operations $p$ and $q$ cannot be executed by the same machining module (turret, at the same machine, respectively).

\section{MIP approach}

In order to solve the considered problem, we developed a Mixed Integer Programming (MIP) model where the following notations are used:

$X_{p k j l}$ decision variable which is equal to 1 if operation $p$ is assigned to the $l$ th machining module of spindle head or turret of type $j$ at station $k, p \in \mathbf{N}, k=1, \ldots, m_{0}, j=1, \ldots, 4, l=1, \ldots, b_{0}$

$h_{r d k}$ decision variable which is equal to 1 if orientation $r$ is chosen for part $d$ at station $k, r=1, \ldots, r d$, $d \in D, k=1, \ldots, m 0$

$Y_{k j}^{d s} \quad$ auxiliary variable which is equal to 1 if at least one machining module of type $j$ is installed at station $k$ for execution of operations from $N_{s}^{d}, d \in D, s=1, \ldots, n_{d}, k=1, \ldots, m_{0}, j=1, \ldots, 4$

$Y_{k j}^{d} \quad$ auxiliary variable which is equal to 1 if at least one machining module of type $j$ is installed at station $k$ for execution of operations from $\mathbf{N}^{d}, d \in D, k=1, \ldots, m_{0}, j=1, \ldots, 4$

$Y_{k j l} \quad$ auxiliary variable which is equal to 1 if the $l$ th machining module of type $j$ is installed at station $k, k=1, \ldots, m 0, j=1, \ldots, 4, l=1, \ldots, b_{0}$

$Y_{k j s} \quad$ auxiliary variable which is equal to 1 if the workhead with a single spindle of type $j$ is installed at station $k, k=1, \ldots, m_{0}, j=1, \ldots, 4$

$Y_{k j b}$ auxiliary variable which is equal to 1 if the spindle box of type $j$ is installed at station $k$, $k=1, \ldots, m 0, j=1, \ldots, 4$

$Z_{k} \quad$ auxiliary variable which is equal to 1 if station $k$ is used, $k=1, \ldots, m 0$

$\rho_{d k k+1}$ auxiliary variable which is equal to 1 if part $d$ is reoriented between stations $k$ and $k+1, d \in D$, $k=1, \ldots, m_{0}-1$

$F_{d k j l} \quad$ execution time for part $d$ by $l$-th machining module of spindle head or turret type $j$ at the $k$-th machine

$F_{d k} \quad$ the execution time for part $d$ at $k$-th machine

$F^{v i} \quad$ total remaining processing time when processing of part $\pi_{\mathrm{v} i}$ of $\mathrm{v}$-th batch is finished

$F_{S}^{\mathrm{v} i} \quad$ total time of first $i$ machines after the $i$-th turn of the conveyer for processing $\mathrm{v}$-th batch

$F_{f}^{\mathrm{v} i} \quad$ total time of last $i$ machines after the $O_{v} \mu_{\mathrm{v}}+m_{0}-i$-th turn of the conveyer for processing $\mathrm{v}$-th batch

$\eta_{\nu} \quad$ number of cyclically repeating part sequences when all machines are occupied $\eta_{v}=\left\llcorner\left(O_{v} \mu_{v^{-}}\right.\right.$ $\left.\left.m_{0}+1\right) / \mu_{v}\right\rfloor$ 
$\theta_{v} \quad$ additional number of part sequences when all machines are occupied $\theta_{v}=\bmod \left(O_{v} \mu_{v}-m_{0}+1, \mu_{v}\right)$

$t_{p q} \quad$ minimal time necessary for the execution of operations $p$ and $q$ by the same machining module, $t_{p q}=\max (\lambda(p), \lambda(q)) / \min \left(\gamma_{2}(p), \gamma_{2}(q)\right)+\tau^{a}$

$M \quad$ an upper bound on the maximal number of operations to be potentially assigned to one machining module $M=\sum_{d=1}^{d_{0}} \max \left\{N_{s}^{d} \mid s=1, \ldots, n_{d}\right\}$

The objective function can be expressed as follows:

$$
\begin{gathered}
\text { Minimize } C_{s m} \sum_{k=1}^{m_{0}} Z_{k}+\sum_{k=1}^{m_{0}} \sum_{j=1}^{4}\left(C_{s b} Y_{k j b}+\left(C_{t b}+2 C_{m m}\right) Y_{k j 2}+C_{s t} Y_{k j s}\right)+ \\
C_{m m} \sum_{k=1}^{m_{0}} \sum_{j=1}^{4} \sum_{l=3}^{b_{0}} Y_{k j l}+C_{r o} \sum_{k=1}^{m_{0}-1} \sum_{d \in D} \rho_{d k k+1}
\end{gathered}
$$

The following equations determine decision variables $X_{p k j l}$ as well as auxiliary variables $Y_{k j}^{d s}, Y_{k j l}$, and $Z_{k}$.

$$
\begin{aligned}
& \sum_{k=1}^{m_{0}} \sum_{j=1}^{4} \sum_{l=1}^{n_{0}} X_{p k j l}=1 ; p \in \mathbf{N} \\
& X_{p k j l}=0 ; j=1, \ldots, 4 ; j \notin J(p) \\
& \sum_{k^{\prime}=1}^{k-1} \sum_{j=1}^{4} \sum_{l=1}^{b_{0}} X_{p k^{\prime} j^{\prime} l^{\prime}}+\sum_{l^{\prime}=1}^{l-1} X_{p k j l^{\prime}} \geq X_{q k j l} ;(p, q) \in D^{O R} ; k=1, \ldots, m_{0} ; j=1, \ldots, 4 ; l=1, \ldots, b_{0} \\
& X_{p k j l}=X_{q k j l} ;\{p, q\} \in E^{S M} \cup E^{S S} ; k=1, \ldots, m_{0} ; j=1, \ldots, 4 ; l=1, \ldots, b_{0} \\
& \sum_{l=1}^{b_{0}} X_{p k j l}=\sum_{l=1}^{b_{0}} X_{q k j l} ;\{p, q\} \in E^{S T} ; k=1, \ldots, m 0 ; j=1, \ldots, 4 \\
& \sum_{j=1}^{4} \sum_{l=1}^{b_{0}} X_{p k j l}=\sum_{j=1}^{4} \sum_{l=1}^{b_{0}} X_{q k j l} ;\{p, q\} \in E^{S P} ; k=1, \ldots, m_{0} \\
& X_{p k j l}+X_{q k j l} \leq 1 ;\{p, q\} \in E^{D M} ; k=1, \ldots, m_{0} ; j=1, \ldots, 4 ; l=1, \ldots, b_{0} \\
& \sum_{l=1}^{b_{0}} X_{p k j l}+\sum_{l=1}^{b_{0}} X_{q k j l}+Y_{k j 2} \leq 2 ;\{p, q\} \in E^{D T} ; k=1, \ldots, m_{0} ; j=1, \ldots, 4 \\
& \sum_{j=1}^{4} \sum_{l=1}^{b_{0}} X_{p k j l}+\sum_{j=1}^{4} \sum_{l=1}^{b_{0}} X_{q k j l} \leq 1 ;\{p, q\} \in E^{D P} ; k=1, \ldots, m_{0} \\
& \sum_{l=1}^{b_{0}} \sum_{p \in N_{s}^{d}} X_{p k j l} \leq\left|N_{s}^{d}\right| Y_{k j}^{d s} ; Y_{k j}^{d s} \leq \sum_{l=1}^{b_{0}} \sum_{p \in N_{s}^{d}} X_{p k j l} ; d \in D ; s=1, \ldots, n_{d} ; k=1, \ldots, m_{0}, j=1, \ldots, 4
\end{aligned}
$$




$$
\begin{gathered}
\sum_{j=1}^{4} Y_{k j}^{d s} \leq 1, d \in D ; s=1, \ldots, n_{d} ; k=1, \ldots, m_{0} \\
\sum_{s=1}^{n_{d}} Y_{k j}^{d s} \leq 1, d \in D ; k=1, \ldots, m 0 ; j=1, \ldots, 4 \\
Y_{k j l} \leq \sum_{p \in \mathbf{N}} X_{p k j l} ; \sum_{p \in \mathbf{N}} X_{p k j l} \leq|\mathbf{N}| Y_{k j l} ; k=1, \ldots, m 0 ; j=1, \ldots, 4 ; l=1, \ldots, b_{0} \\
Y_{k j l} \geq Y_{k j l+1} ; k=1, \ldots, m 0 ; j=1, \ldots, 4 ; l=1, \ldots, b_{0}-1 \\
\sum_{j=1}^{4} Y_{k j 1} \leq 3 ; \sum_{j=1}^{4} Y_{k j 1} \leq 3 Z_{k} ; Z k \leq \sum_{j=1}^{4} Y_{k j 1} ; k=1, \ldots, m 0 \\
\sum_{p \in \mathbf{N}} X_{p k j 1}+Y_{k j 2}+M Y_{k j s} \leq M+1, k=1, \ldots, m 0 ; j=1, \ldots, 4 \\
Y_{k j b}+Y_{k j 2}+Y_{k j s}=Y_{k j 1}, k=1, \ldots, m 0 ; j=1, \ldots, 4 \\
Z_{k} \leq Z_{k-1} ; k=2, \ldots, m 0
\end{gathered}
$$

Constraints (2) - (3) guarantee an assignment of each operation to exactly one machining module of compatible type. Precedence constraints, inclusion constraints for spindles, machining modules, turrets and machines as well as exclusion constraints for machining modules, turrets and machines are provided by (4) - (10) respectively. Constraints (11) - (12) prevent from an assignment of operations located at the same side of each part to machining modules of different types of the same machine. Constraints (13) (19) define the configuration of machines, workheads with single spindle, spindle boxes, turrets, and corresponding machining modules. A workhead with single spindle is installed $\left(Y_{k j s}=1\right)$ if and only if $\sum_{p \in \mathbf{N}} X_{p k j 1}=1, Y_{k j 1}=1, Y_{k j b}=0$ and $Y_{k j 2}=0$. If $Y_{k j 2}=1$ (a turret is installed), then $Y_{k j b}=0$ and $Y_{k j s}=0$.

Decision variables $h_{r d k}$ and auxiliary variables $\rho_{d k k+1}$ are defined by the following constraints:

$$
\begin{gathered}
h_{r d k}+Y_{k j}^{d s} \leq 1 ; r=1, \ldots, r d ; d \in D ; k=1, \ldots, m 0 ; s=1, \ldots, n_{d} ; j=1, \ldots, 4 ; j \neq h_{r s}(d) \\
\sum_{r=1}^{r_{d}} h_{r d k}=1 ; d \in D ; k=1, \ldots, m 0 \\
r_{d} \rho_{d k k+1} \geq \sum_{r=1}^{r_{d}} r h_{r d k}-\sum_{r=1}^{r_{d}} r h_{r d k+1} ; r_{d} \rho_{d k k+1} \geq \sum_{r=1}^{r_{d}} r h_{r d k+1}-\sum_{r=1}^{r_{d}} r h_{r d k} ; d \in D ; k=1, \ldots, m_{0}-1
\end{gathered}
$$

Constraints (20) - (21) defines the orientation of each part at each machine. Variables $\rho d k k+1$ are equal to 0 if $h_{r d k}=h_{r d k+1}$ for all $r=1, \ldots, r_{d}$ due to (22) and minimization of (1). 
The required productivity is provided if the following constraints are satisfied:

$$
\begin{gathered}
F_{d k j l} \geq t_{p p} X_{p k j l} ; p \in \mathbf{N}^{d} ; d \in D ; k=1, \ldots, m 0 ; j=1, \ldots 4 ; l=1, \ldots, b_{0} \\
F_{d k j l} \geq t_{p q}\left(X_{p k j l}+X_{q k j l}-1\right) ; p, q \in \mathbf{N}^{d} ; d \in D ; k=1, \ldots, m_{0} ; j=1, \ldots, 4 ; l=1, \ldots, b_{0} \\
F_{d k} \geq \sum_{l=1}^{b_{0}} F_{d k j l}+\tau^{g}\left(2 Y_{k j 2}+\sum_{l=3}^{b_{0}} Y_{k j l}\right)+b_{0} \tau^{g}\left(Y_{k j}^{d}-1\right) ; d \in D ; k=1, \ldots, m 0 ; j=1, \ldots, 4 \\
F^{\mathrm{vi}} \geq F_{k}^{\pi_{\mathrm{v}}\left(m_{0}+i-1, k\right)}+\tau^{r} ; \mathrm{v}=1, \ldots, \aleph ; i=1, \ldots, \mu_{\mathrm{v}} ; k=1, \ldots, m_{0} \\
F_{S}^{\mathrm{v} i} \geq F_{k}^{\pi_{\mathrm{v}}(i, k)}+\tau^{r} ; \mathrm{v}=1, \ldots, \aleph ; i=1, \ldots, m_{0}-1 ; k=1, \ldots, i \\
F_{f}^{\mathrm{v} i} \geq F_{k}^{\pi_{\mathrm{v}}\left(O_{\mathrm{v}} \mu_{\mathrm{v}}+m_{0}-i, k\right)}+\tau^{r} ; \mathrm{v}=1, \ldots, \aleph ; i=2, \ldots, m_{0} ; k=i, \ldots, m_{0} \\
\sum_{\mathrm{v}=1}^{\aleph}\left(\eta_{\mathrm{v}} \sum_{i=1}^{\mu_{\mathrm{v}}} F^{\mathrm{v} i}+\sum_{i=1}^{\theta_{\mathrm{v}}} F^{\mathrm{v} i}+\sum_{i=1}^{m_{0}-1} F_{S}^{\mathrm{v} i}+\sum_{i=2}^{m_{0}} F_{f}^{\mathrm{v} i}\right) \leq T_{0}
\end{gathered}
$$

Constraints (21) - (22) calculate the execution time of the $l$-th machining module of type $j$ at the $k$-th machine for processing part $d$. If a turret of type $j$ with $b_{k j}$ machining modules is installed at the $k$-th machine then: $F_{d k} \geq \sum_{l=1}^{b_{k j}} F_{k j l}^{d}+b_{0} \tau^{g}$ due to (25) if at least one operation from $\mathrm{N}^{d}$ is executed by the turret and $F_{d k}=0$, otherwise. If a spindle head of type $j$ is installed at the $k$-th machine then $F_{d k} \geq F_{k j 1}^{d}$.

Variables domains are defined as follows:

$$
\begin{gathered}
X_{p k j l} \in\{0,1\} ; p \in \mathbf{N} ; k=1, \ldots, m_{0} ; j=1, \ldots, 4 ; l=1, \ldots, b_{0} \\
Y_{k j}^{d s} \in\{0,1\} ; k=1, \ldots, m_{0} ; d \in D ; s=1, \ldots, n_{d} ; j=1, \ldots, 4 \\
Y_{k j}^{d} \in\{0,1\} ; k=1, \ldots, m 0 ; d \in D ; j=1, \ldots, 4 \\
Y_{k j l}^{d} \in\{0,1\} ; k=1, \ldots, m_{0} ; j=1, \ldots, 4 ; l=1, \ldots, b_{0} ; d \in D \\
Y_{k j l} \in\{0,1\} ; k=1, \ldots, m_{0} ; j=1, \ldots, 4 ; l=1, \ldots, b_{0} \\
Z Z k \in\{0,1\} ; k=1, \ldots, m 0 \\
h_{r d k} \in\{0,1\} ; r=1, \ldots, r d ; d \in D ; k=1, \ldots, m_{0} \\
\rho_{d k k+1} \in\{0,1\} ; d \in D ; k=1, \ldots, m_{0}-1 \\
F_{k j l}^{d} \in\left[0, \bar{t}_{k}^{d}-\tau^{r}\right] ; k=1, \ldots, m_{0} ; j=1, \ldots, 4 ; l=1, \ldots, b_{0} ; d \in D
\end{gathered}
$$




$$
\begin{gathered}
F_{k}^{d} \in\left[0, \bar{t}_{k}^{d}-\tau^{r}\right] ; k=1, \ldots, m_{0} ; d \in D \\
F^{\mathrm{v} i} \in\left[\underline{t}^{\mathrm{v} i}, \bar{t}^{\mathrm{v} i}\right] ; \mathrm{v}=1, \ldots, \aleph ; i=1, \ldots, \mu_{\mathrm{v}} \\
F_{S}^{\mathrm{v} i} \in\left[\max \left\{\underline{t}^{\pi_{\mathrm{v}}(i, k)} \mid k=1, \ldots, i\right\}, \max \left\{\bar{t}_{k}^{\pi_{\mathrm{v}}(i, k)} \mid k=1, \ldots, i\right\}\right] ; \mathrm{v}=1, \ldots, \aleph ; i=1, \ldots, m_{0}-1 \\
F_{f}^{\mathrm{v} i} \in\left[\max \left\{\underline{t}_{\mathrm{v}}^{\pi_{\mathrm{v}}}\left(O_{\mathrm{v}} \mu_{\mathrm{v}}-i, k\right) \mid k=i, \ldots, m_{0}\right\}, \max \left\{\bar{t}_{k}^{\pi_{\mathrm{v}}}\left(O_{\mathrm{v}} \mu_{\mathrm{v}}-i, k\right) \mid k=i, \ldots, m_{0}\right\}\right] ; \mathrm{v}=1, \ldots, \aleph ; i=2, \ldots, m_{0}
\end{gathered}
$$

where

$\underline{t}^{d}=\min \left\{\lambda(p) / \gamma_{2}(p)+\tau^{a}+\tau^{r} \mid p \in \mathbf{N}^{d}\right\}$

$\underline{t}^{\mathrm{v} i}=\max \left\{\underline{t}^{\pi_{\mathrm{v}}(i, k)} \mid k=1, \ldots, m_{0}\right\}$

$\bar{t}^{\mathrm{v} i}=\left(T_{0}-O_{\mathrm{v}^{\prime}} \sum_{\mathrm{v}^{\prime}=1, \mathrm{v}^{\prime} \neq \mathrm{v}}^{\stackrel{N}{N}} \sum_{i^{\prime}=1}^{\mu_{\mathrm{v}^{\prime}}} \underline{t}^{\mathrm{v}^{\prime} i^{\prime}}\right) / O_{\mathrm{v}}-\sum_{i^{\prime}=1, i^{\prime} \neq i}^{\mu_{\mathrm{v}}} \underline{t}^{\mathrm{v} i^{\prime}}$

and

$\bar{t}_{k}^{d}=\max \left\{\bar{t}^{\mathrm{v} i} \mid \mathrm{v}=1, \ldots, \aleph, i=1, \ldots, O_{\mathrm{v}} \mu_{\mathrm{v}}+m_{0}-1, \pi_{\mathrm{v}}(i, k)=d\right\}$.

\section{A case study}

In order to validate the developed model, it was used to design a flow line for machining 3 different parts (Fig. 3 to Fig. 5) in 2 batches with $O_{1}=34$ and $O_{2}=68$. The parameters of machining operations are given in Table 1. The operations to be executed for the first part are located on 4 different sides and those for the second and third parts are located on only 3 sides. The loading sequences of parts are $\{1,2\}$ and $\{3\}$. Other parameters are: $\tau^{a}=\tau^{g}=\tau^{r}=0.1 \mathrm{~min}, \mathrm{C}_{s m}=20, \mathrm{C}_{s h}=4, \mathrm{C}_{t b}=5, \mathrm{C}_{m m}=2, \mathrm{C}_{r o}=0.5$. The available time $T_{0}$ is $384 \mathrm{~min}$. The possible orientations of the parts are defined as follows:

$$
\mathbf{H}(1)=\left(\begin{array}{cccc}
-1 & 1 & 4 & -1 \\
4 & 1 & -1 & -1 \\
4 & -1 & -1 & 1 \\
-1 & -1 & 4 & 1 \\
1 & 2 & -1 & -1
\end{array}\right), \mathbf{H}(2)=\left(\begin{array}{ccc}
-1 & 1 & 4 \\
4 & 1 & -1 \\
1 & 2 & -1
\end{array}\right), \mathbf{H}(3)=\left(\begin{array}{ccc}
-1 & 1 & 2 \\
-1 & 1 & 4 \\
2 & -1 & -1 \\
4 & -1 & -1
\end{array}\right)
$$



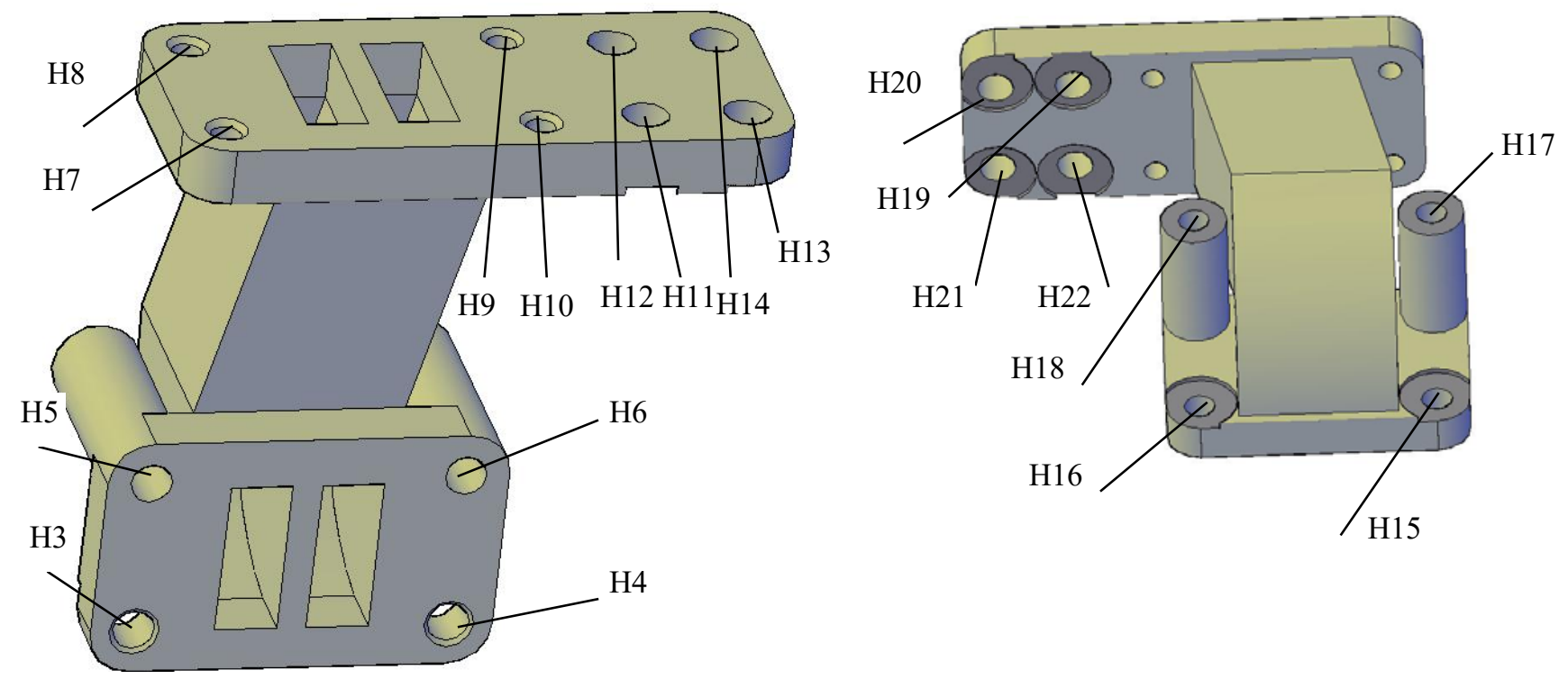

Fig.3. The first part to be machined
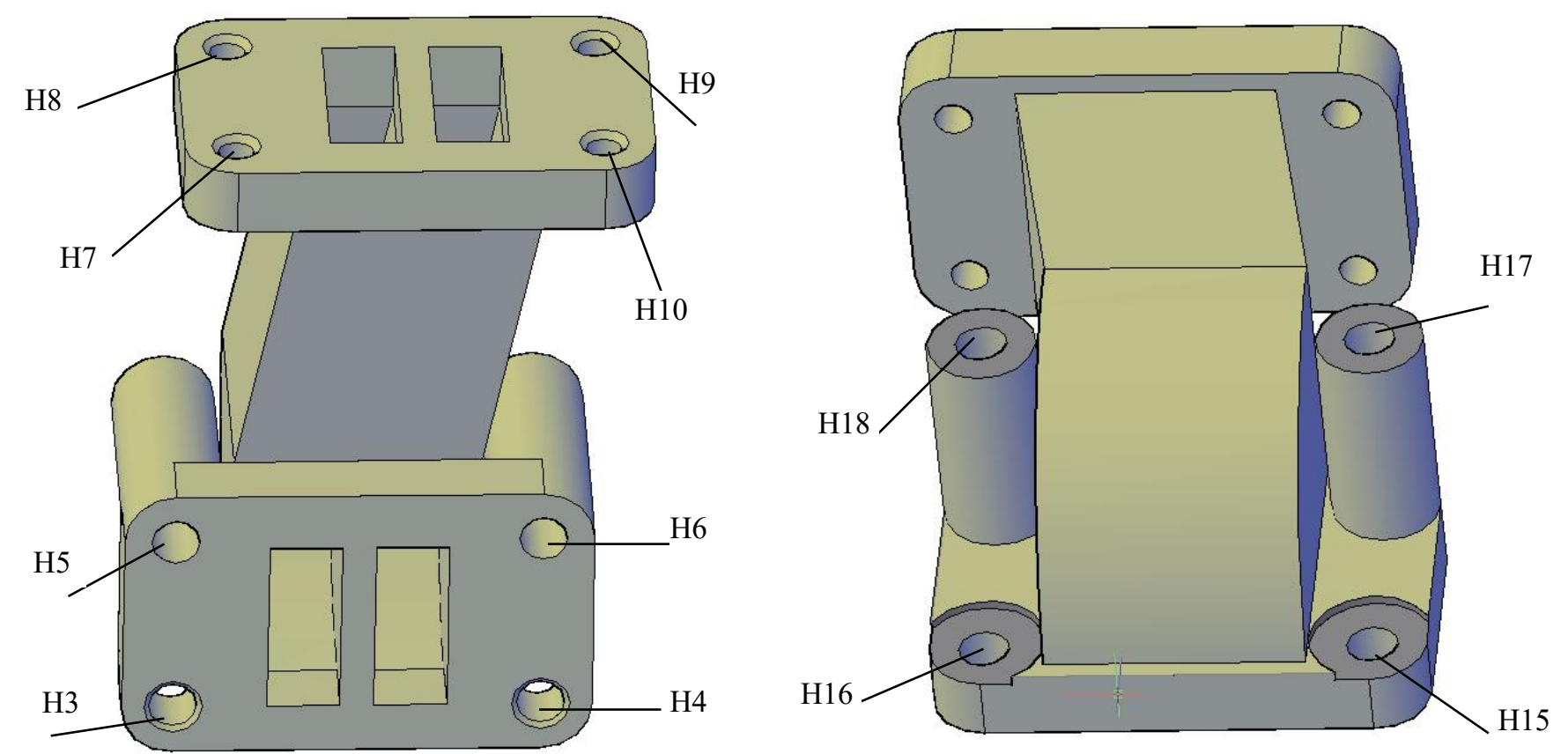

Fig.4. The second part to be machined
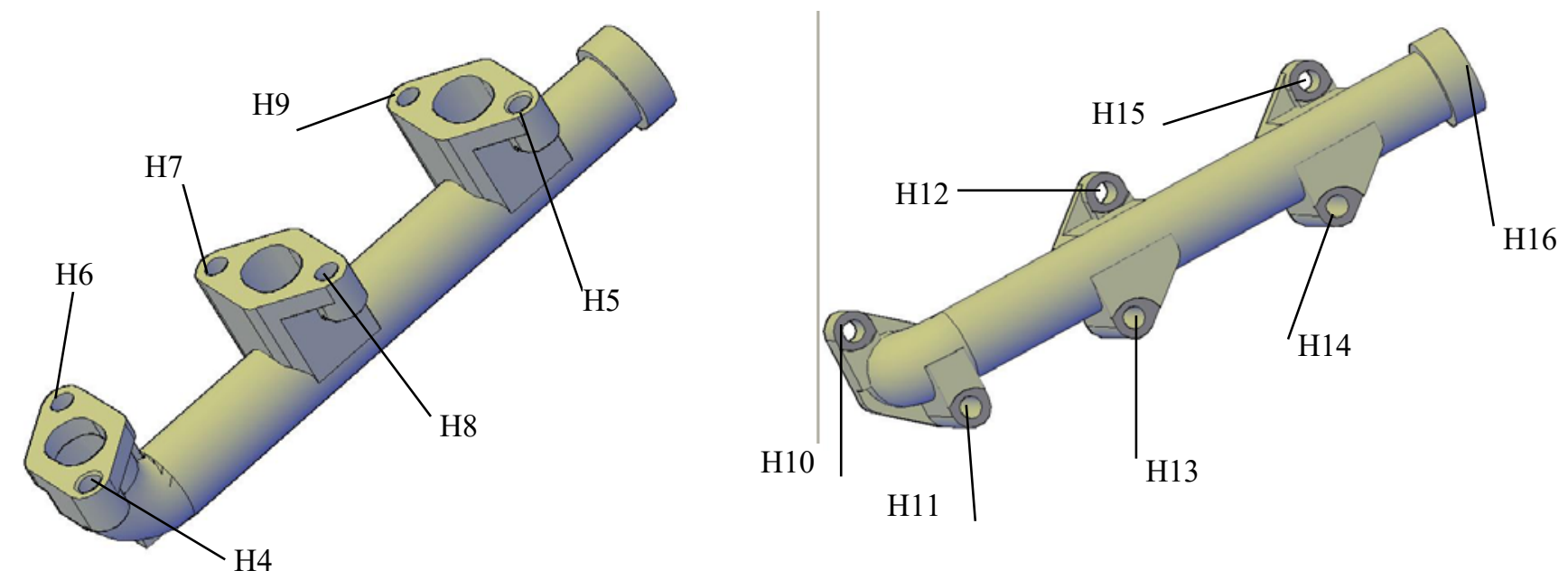

Fig.5. The third part to be machined 
Table 1. Operations and their parameters

\begin{tabular}{|c|c|c|c|c|c|c|c|c|c|c|c|c|c|c|c|}
\hline$p$ & Hole & Part & Side & $\begin{array}{l}\lambda(p) \\
\mathrm{mm}\end{array}$ & $\begin{array}{l}\gamma_{1}(p), \\
\mathrm{mm} / \\
\mathrm{min}\end{array}$ & $\begin{array}{l}\gamma_{2}(p), \\
\mathrm{mm} / \\
\mathrm{min}\end{array}$ & $J(p)$ & $p$ & Hole & Part & Side & $\begin{array}{l}\lambda(p) \\
\mathrm{mm}\end{array}$ & $\begin{array}{l}\gamma_{1}(p), \\
\mathrm{mm} / \\
\mathrm{min}\end{array}$ & $\begin{array}{l}\gamma_{2}(p), \\
\mathrm{mm} / \\
\mathrm{min}\end{array}$ & $J(p)$ \\
\hline 1 & H3 & 1 & 1 & 34 & 37.7 & 63.4 & $\{1,4\}$ & 36 & H6 & 2 & 1 & 75 & 29.7 & 105.7 & $\{1,4\}$ \\
\hline 2 & H3 & 1 & 1 & 22 & 27.8 & 249.5 & $\{1,4\}$ & 37 & H7 & 2 & 2 & 24 & 24.6 & 83.6 & $\{1,2\}$ \\
\hline 3 & H4 & 1 & 1 & 34 & 37.7 & 63.4 & $\{1,4\}$ & 38 & H7 & 2 & 2 & 9 & 28.3 & 106.3 & $\{1,2\}$ \\
\hline 4 & H4 & 1 & 1 & 22 & 27.8 & 249.5 & $\{1,4\}$ & 39 & H8 & 2 & 2 & 24 & 24.6 & 83.6 & $\{1,2\}$ \\
\hline 5 & H5 & 1 & 1 & 79 & 22.8 & 81.3 & $\{1,4\}$ & 40 & H8 & 2 & 2 & 9 & 28.3 & 106.3 & $\{1,2\}$ \\
\hline 6 & H5 & 1 & 1 & 75 & 29.7 & 105.7 & $\{1,4\}$ & 41 & H9 & 2 & 2 & 24 & 24.6 & 83.6 & $\{1,2\}$ \\
\hline 7 & H6 & 1 & 1 & 79 & 22.8 & 81.3 & $\{1,4\}$ & 42 & H9 & 2 & 2 & 9 & 28.3 & 106.3 & $\{1,2\}$ \\
\hline 8 & H6 & 1 & 1 & 75 & 29.7 & 105.7 & $\{1,4\}$ & 43 & $\mathrm{H} 10$ & 2 & 2 & 24 & 24.6 & 83.6 & $\{1,2\}$ \\
\hline 9 & H7 & 1 & 2 & 24 & 24.6 & 83.6 & $\{1,2\}$ & 44 & H10 & 2 & 2 & 9 & 28.3 & 106.3 & $\{1,2\}$ \\
\hline 10 & H7 & 1 & 2 & 9 & 28.3 & 106.3 & $\{1,2\}$ & 45 & H15 & 2 & 3 & 2 & 18.8 & 62.7 & $\{4\}$ \\
\hline 11 & H8 & 1 & 2 & 24 & 24.6 & 83.6 & $\{1,2\}$ & 46 & H16 & 2 & 3 & 2 & 18.8 & 62.7 & $\{4\}$ \\
\hline 12 & H8 & 1 & 2 & 9 & 28.3 & 106.3 & $\{1,2\}$ & 47 & H17 & 2 & 3 & 2 & 18.8 & 62.7 & $\{4\}$ \\
\hline 13 & H9 & 1 & 2 & 24 & 24.6 & 83.6 & $\{1,2\}$ & 48 & H18 & 2 & 3 & 2 & 18.8 & 62.7 & $\{4\}$ \\
\hline 14 & H9 & 1 & 2 & 9 & 28.3 & 106.3 & $\{1,2\}$ & 49 & H4 & 3 & 1 & 53 & 39.2 & 62.9 & $\{2,4\}$ \\
\hline 15 & H10 & 1 & 2 & 24 & 24.6 & 83.6 & $\{1,2\}$ & 50 & $\mathrm{H} 4$ & 3 & 1 & 34 & 27.2 & 248 & $\{2,4\}$ \\
\hline 16 & $\mathrm{H} 10$ & 1 & 2 & 9 & 28.3 & 106.3 & $\{1,2\}$ & 51 & H5 & 3 & 1 & 53 & 39.2 & 62.9 & $\{2,4\}$ \\
\hline 17 & H11 & 1 & 2 & 25 & 22 & 82.2 & $\{1,2\}$ & 52 & H5 & 3 & 1 & 34 & 27.2 & 248 & $\{2,4\}$ \\
\hline 18 & H12 & 1 & 2 & 25 & 22 & 82.2 & $\{1,2\}$ & 53 & H6 & 3 & 1 & 100 & 22.8 & 81.3 & $\{2,4\}$ \\
\hline 19 & H13 & 1 & 2 & 25 & 22 & 82.2 & $\{1,2\}$ & 54 & H6 & 3 & 1 & 98 & 29.7 & 105.7 & $\{2,4\}$ \\
\hline 20 & H14 & 1 & 2 & 25 & 22 & 82.2 & $\{1,2\}$ & 55 & $\mathrm{H} 7$ & 3 & 1 & 100 & 22.8 & 81.3 & $\{2,4\}$ \\
\hline 21 & H15 & 1 & 3 & 2 & 18.8 & 62.7 & $\{4\}$ & 56 & H7 & 3 & 1 & 98 & 29.7 & 105.7 & $\{2,4\}$ \\
\hline 22 & H16 & 1 & 3 & 2 & 18.8 & 62.7 & $\{4\}$ & 57 & H8 & 3 & 1 & 45 & 22.8 & 81.3 & $\{2,4\}$ \\
\hline 23 & H17 & 1 & 3 & 2 & 18.8 & 62.7 & $\{4\}$ & 58 & H8 & 3 & 1 & 43 & 29.7 & 105.7 & $\{2,4\}$ \\
\hline 24 & H18 & 1 & 3 & 2 & 18.8 & 62.7 & $\{4\}$ & 59 & H9 & 3 & 1 & 100 & 22.8 & 81.3 & $\{2,4\}$ \\
\hline 25 & H19 & 1 & 4 & 2 & 18.8 & 62.7 & $\{1\}$ & 60 & H9 & 3 & 1 & 98 & 29.7 & 105.7 & $\{2,4\}$ \\
\hline 26 & $\mathrm{H} 20$ & 1 & 4 & 2 & 18.8 & 62.7 & $\{1\}$ & 61 & H10 & 3 & 2 & 3 & 15.5 & 51.6 & $\{1\}$ \\
\hline 27 & $\mathrm{H} 21$ & 1 & 4 & 2 & 18.8 & 62.7 & $\{1\}$ & 62 & H11 & 3 & 2 & 3 & 15.5 & 51.6 & $\{1\}$ \\
\hline 28 & H22 & 1 & 4 & 2 & 18.8 & 62.7 & $\{1\}$ & 63 & H12 & 3 & 2 & 3 & 15.5 & 51.6 & $\{1\}$ \\
\hline 29 & H3 & 2 & 1 & 34 & 37.7 & 63.4 & $\{1,4\}$ & 64 & $\mathrm{H} 13$ & 3 & 2 & 3 & 15.5 & 51.6 & $\{1\}$ \\
\hline 30 & H3 & 2 & 1 & 22 & 27.8 & 249.5 & $\{1,4\}$ & 65 & H14 & 3 & 2 & 3 & 15.5 & 51.6 & $\{1\}$ \\
\hline 31 & H4 & 2 & 1 & 34 & 37.7 & 63.4 & $\{1,4\}$ & 66 & H15 & 3 & 2 & 3 & 15.5 & 51.6 & $\{1\}$ \\
\hline 32 & H4 & 2 & 1 & 22 & 27.8 & 249.5 & $\{1,4\}$ & 67 & H16 & 3 & 2 & 30 & 43.7 & 74.1 & $\{2,4\}$ \\
\hline 33 & H5 & 2 & 1 & 79 & 22.8 & 81.3 & $\{1,4\}$ & 68 & H16 & 3 & 5 & 24 & 31.9 & 197.1 & $\{2,4\}$ \\
\hline 34 & H5 & 2 & 1 & 75 & 29.7 & 105.7 & $\{1,4\}$ & 69 & H16 & 3 & 5 & 24 & 26.9 & 161.6 & $\{2,4\}$ \\
\hline 35 & H6 & 2 & 1 & 79 & 22.8 & 81.3 & $\{1,4\}$ & 70 & H16 & 3 & 5 & 18 & 26.7 & 160.2 & $\{2,4\}$ \\
\hline
\end{tabular}

Precedence constraints, exclusion constraints for machining modules, turrets and machines are presented in Tables 2, 3, 4, and 5, respectively. Inclusion constraints for machines, turrets and machining modules are given in Tables 6,7 and 8. Operations to be executed by the same spindle are presented in Table 9. 
Table 2. Precedence constraints

\begin{tabular}{llll}
\hline Operation & Predecessors & Operation & Predecessors \\
\hline 2 & 132931 & 40 & 911131537394143 \\
4 & 132931 & 42 & 911131537394143 \\
6 & 573335 & 44 & 911131537394143 \\
8 & 573335 & 50 & 4951 \\
10 & 911131537394143 & 52 & 4951 \\
12 & 911131537394143 & 54 & 535559 \\
14 & 911131537394143 & 56 & 535559 \\
16 & 911131537394143 & 58 & 57 \\
30 & 132931 & 60 & 535559 \\
32 & 132931 & 68 & 67 \\
34 & 573335 & 69 & 68 \\
36 & 573335 & 70 & 69 \\
38 & 911131537394143 & & \\
\hline
\end{tabular}

Table 3. Incompatibility of operations in machining modules

\begin{tabular}{ll}
\hline Operation & Incompatible operations \\
\hline $9 / 10 / 11 / 12 / 13 / 14 / 15 / 16$ & 12345678 \\
17 & 123456781314 \\
18 & 1234567817 \\
19 & 1234567818 \\
20 & 1234567815161719 \\
$21 / 22$ & 1234567891011121314151617181920 \\
23 & 123456789101112131415161718192021 \\
24 & 123456789101112131415161718192022 \\
25 & 123456789101112131415161718192021222324 \\
26 & 12345678910111213141516171819202122232425 \\
27 & 1234567891011121314151617181920212223242526 \\
28 & 123456789101112131415161718192021222324252627 \\
$37 / 38 / 39 / 40 / 41 / 42 / 43 / 44$ & 2930313233343536 \\
$45 / 46$ & 29303132333435363738394041424344 \\
47 & 2930313233343536373839404142434445 \\
48 & 2930313233343536373839404142434446 \\
$61 / 62 / 63 / 64 / 66$ & 495051525354555657585960 \\
$67 / 68 / 69 / 70$ & 495051525354555657585960616263646566 \\
\hline
\end{tabular}

Table 4. Incompatibility of operations in turrets

\begin{tabular}{ll}
\hline Operation & Incompatible operations \\
\hline $9 / 10 / 11 / 12 / 13 / 14 / 15 / 16 / 17 / 18 / 19 / 20$ & 12345678 \\
$21 / 22 / 23 / 24$ & 1234567891011121314151617181920 \\
$25 / 26 / 27 / 28$ & 123456789101112131415161718192021222324 \\
$37 / 38 / 39 / 40 / 41 / 42 / 43 / 44$ & 2930313233343536 \\
$45 / 46 / 47 / 48$ & 29303132333435363738394041424344 \\
$61 / 62 / 63 / 64 / 65 / 66$ & 495051525354555657585960 \\
$67 / 68 / 69 / 70$ & 495051525354555657585960616263646566 \\
\hline
\end{tabular}

Table 5. Incompatibility of operations in machines

\begin{tabular}{ll}
\hline Operation & Incompatible operations \\
\hline $1 / 2 / 3 / 4 / 5 / 6 / 7 / 8$ & 21222324 \\
$17 / 18 / 19 / 20$ & 25262728 \\
$49 / 50 / 51 / 52 / 53 / 54 / 55 / 56 / 57 / 58 / 59 / 60$ & 616263646566 \\
\hline
\end{tabular}


Table 6. Operations to be assigned to the same machine

\begin{tabular}{llll}
\hline Operation & $\begin{array}{c}\text { Operations to be executed at the same } \\
\text { machine }\end{array}$ & Operation & $\begin{array}{c}\text { Operations to be executed at the same } \\
\text { machine }\end{array}$ \\
\hline 49 & 5153555759 & 50 & 5254565860 \\
\hline
\end{tabular}

Table 7. Operations to be assigned to the same turret

\begin{tabular}{llll}
\hline Operation & Operations to be executed by the same & Operation & Operations to be executed by the same \\
turret & 67 & 686970 & \\
\hline 25 & 262728 & 67 & \\
\hline
\end{tabular}

Table 8. Operations to be assigned to the same machining module

\begin{tabular}{llll}
\hline Operation & $\begin{array}{c}\text { Operations to be executed by the same } \\
\text { machining module }\end{array}$ & Operation & $\begin{array}{c}\text { Operations to be executed by the same } \\
\text { machining module }\end{array}$ \\
\hline 1 & 3 & 33 & 35 \\
5 & 7 & 34 & 36 \\
6 & 8 & 37 & 394143 \\
9 & 111315 & 49 & 51 \\
17 & 19 & 53 & 5559 \\
18 & 20 & 54 & 5660 \\
29 & 31 & & \\
\hline
\end{tabular}

Table 9. Operations to be executed by the same spindle

\begin{tabular}{|c|c|c|c|}
\hline Operation & $\begin{array}{l}\text { Operations to be executed by the same } \\
\text { tool }\end{array}$ & Operation & $\begin{array}{l}\text { Operations to be executed by the same } \\
\text { tool }\end{array}$ \\
\hline 1 & 29 & 11 & 39 \\
\hline 2 & 30 & 12 & 40 \\
\hline 3 & 31 & 13 & 41 \\
\hline 4 & 32 & 14 & 42 \\
\hline 5 & 33 & 15 & 43 \\
\hline 6 & 34 & 16 & 44 \\
\hline 7 & 35 & 21 & 45 \\
\hline 8 & 36 & 22 & 46 \\
\hline 9 & 37 & 23 & 47 \\
\hline 10 & 38 & 24 & 48 \\
\hline
\end{tabular}

Solver CPLEX 12.2 was used to solve the corresponding problems (1) - (42) for $b_{0}=4$ and $m_{0}=2,3,4,5$ on PC Intel Pentium (2.40 Ghz, 4 Gb RAM). The obtained results are presented in Table 10.

Table 10. Results of optimization

\begin{tabular}{cccc}
\hline$m_{0}$ & Number of variables & Number of constraints & Solution time, $\mathrm{s}$ \\
\hline 2 & 1639 & 49700 & 8.18 \\
3 & 2458 & 74553 & 20.13 \\
4 & 3277 & 99406 & 40.51 \\
5 & 4096 & 124259 & 56.82 \\
\hline
\end{tabular}


In all obtained solutions the flow line consists of 2 machines and 2 turrets should be installed at each machine but the assignment of operations to machining modules is quite different. The obtained optimal solution for $m_{0}=5$ and its characteristics are presented in Tables 11 and 12 . The total cost $Q(P)$ is equal to $2 \mathrm{C}_{s m}+0 \mathrm{C}_{s h}+4 \mathrm{C}_{t b}+12 \mathrm{C}_{m m}+3 \mathrm{C}_{r o} 5=85.5$. In this case $p_{1}=32, p_{2}=64, \eta_{1}=\eta_{2}=0$. The total time $T(P)$ is equal to $32(2.46+2.46)+1.03+2.46+2.46+2.46+2.46+64(3.02)+3.02+3.02+3.02+3.02+1.96=375.63 \mathrm{~min}$.

Table 11. An optimal solution

\begin{tabular}{lllll}
\hline Set $N_{d k j l}$ & \multicolumn{1}{c}{ Operations of $N_{d k j l}$} & \multicolumn{1}{c}{$L\left(N_{d k j l}\right)$} & $\gamma_{d k j l}$ & $t^{b}\left(P_{d k j l}\right)$ \\
\hline$N_{1111}$ & 25 & 2 & 62.7 & 0.13 \\
$N_{1112}$ & 27 & 2 & 62.7 & 0.13 \\
$N_{1113}$ & 28 & 2 & 62.7 & 0.13 \\
$N_{1114}$ & 26 & 2 & 62.7 & 0.13 \\
$N_{1141}$ & 2124 & 2 & 62.7 & 0.13 \\
$N_{2141}$ & 4548 & 2 & 62.7 & 0.13 \\
$N_{3141}$ & 495153555957 & 100 & 62.9 & 1.69 \\
$N_{1142}$ & 2223 & 2 & 62.7 & 0.13 \\
$N_{2142}$ & 4647 & 2 & 62.7 & 0.13 \\
$N_{3142}$ & 50525456658 & 98 & 105.7 & 1.03 \\
$N_{1211}$ & 1357 & 79 & 63.4 & 1.35 \\
$N_{2211}$ & 29313335 & 79 & 63.4 & 1.35 \\
$N_{1212}$ & 2468 & 75 & 105.7 & 0.81 \\
$N_{2212}$ & 30323436 & 75 & 105.7 & 0.81 \\
$N_{3212}$ & 616263646566 & 3 & 51.6 & 0.16 \\
$N_{3221}$ & 67 & 40 & 74.1 & 0.77 \\
$N_{1222}$ & 9111315 & 24 & 83.6 & 0.39 \\
$N_{2222}$ & 37394143 & 24 & 83.6 & 0.39 \\
$N_{3222}$ & 68 & 24 & 197.1 & 0.22 \\
$N_{1223}$ & 12141820 & 25 & 82.2 & 0.4 \\
$N_{2223}$ & 4042 & 9 & 106.3 & 0.18 \\
$N_{3223}$ & 69 & 24 & 161.6 & 0.25 \\
$N_{1224}$ & 10161719 & 25 & 82.2 & 0.4 \\
$N_{2224}$ & 3844 & 9 & 106.3 & 0.18 \\
$N_{3224}$ & 70 & & & \\
\hline & & 9 & &
\end{tabular}

Table 12. Characteristics of the solution

\begin{tabular}{lllllrl}
\hline Machine $k$ & $t^{p}\left(P_{1 k}\right)$ & $t^{p}\left(P_{2 k}\right)$ & $t^{p}\left(P_{3 k}\right)$ & $H_{1 k}$ & $H_{2 k}$ & \multicolumn{1}{c}{$H_{3 k}$} \\
\hline 1 & 1.03 & 0.56 & 3.02 & $-1,-1,4,1$ & $-1,1,4$ & $4,-1,-1$ \\
2 & 2.46 & 2.46 & 1.96 & $1,2,-1,-1$ & $1,2,-1$ & $-1,1,2$ \\
3 & 0 & 0 & 0 & - & - & - \\
4 & 0 & 0 & 0 & - & - & - \\
5 & 0 & 0 & 0 & - & - & - \\
\hline
\end{tabular}

The proposed approach was also tested on 20 industrial examples with $|\aleph|=2$. The proprieties of these instances are given in Table 9 where $O S^{O R}$ is the order strength of the precedence constraints (the ratio between the number of arcs in the closure of $G^{O R}$ and the number of arcs in the complete digraph with the same number of vertices. Densities of other constraints $\left(D^{D M}, D^{D T}, D^{D P}, D^{S S}, D^{S M}, D^{S T}\right.$, and $\left.D^{S P}\right)$ are defined in the same way. 
Table 9. The proprieties of the industrial examples

\begin{tabular}{lllllllllllll}
\hline Problem & $|\mathbf{N}|$ & $O S^{O R}$ & $D^{D B}$ & $D^{D T}$ & $D^{D P}$ & $D^{S S}$ & $D^{S B}$ & $D^{S T}$ & $D^{S P}$ & $|D|$ & $\sum_{\mathrm{v}=1}^{N} \mu_{\mathrm{v}}$ \\
\hline 1 & & & & & & & & & & & 4 \\
2 & 58 & 0.050 & 0.502 & 0.228 & 0.030 & 0.002 & 0.025 & 0.003 & 0.026 & 2 & 4 \\
3 & 58 & 0.060 & 0.356 & 0.000 & 0.039 & 0.000 & 0.033 & 0.004 & 0.031 & 2 & 4 \\
4 & 50 & 0.020 & 0.358 & 0.257 & 0.015 & 0.002 & 0.030 & 0.000 & 0.016 & 2 & 4 \\
5 & 92 & 0.037 & 0.712 & 0.205 & 0.020 & 0.000 & 0.041 & 0.000 & 0.017 & 2 & 4 \\
6 & 82 & 0.013 & 0.640 & 0.000 & 0.022 & 0.013 & 0.022 & 0.000 & 0.039 & 3 & 4 \\
7 & 100 & 0.034 & 0.515 & 0.224 & 0.018 & 0.006 & 0.018 & 0.001 & 0.022 & 3 & 4 \\
8 & 88 & 0.010 & 0.376 & 0.000 & 0.023 & 0.004 & 0.023 & 0.002 & 0.027 & 3 & 4 \\
9 & 92 & 0.038 & 0.550 & 0.242 & 0.011 & 0.007 & 0.020 & 0.000 & 0.019 & 3 & 4 \\
10 & 80 & 0.013 & 0.408 & 0.000 & 0.015 & 0.005 & 0.026 & 0.000 & 0.023 & 3 & 4 \\
11 & 90 & 0.037 & 0.517 & 0.247 & 0.040 & 0.006 & 0.018 & 0.001 & 0.015 & 3 & 4 \\
12 & 78 & 0.011 & 0.360 & 0.000 & 0.053 & 0.004 & 0.024 & 0.002 & 0.018 & 3 & 4 \\
13 & 80 & 0.041 & 0.524 & 0.233 & 0.043 & 0.006 & 0.022 & 0.002 & 0.010 & 3 & 4 \\
14 & 70 & 0.012 & 0.380 & 0.000 & 0.056 & 0.005 & 0.028 & 0.002 & 0.014 & 3 & 4 \\
15 & 124 & 0.027 & 0.493 & 0.239 & 0.024 & 0.007 & 0.014 & 0.001 & 0.015 & 4 & 4 \\
16 & 108 & 0.008 & 0.335 & 0.000 & 0.032 & 0.005 & 0.018 & 0.001 & 0.019 & 4 & 4 \\
17 & 114 & 0.029 & 0.482 & 0.229 & 0.029 & 0.007 & 0.016 & 0.001 & 0.018 & 4 & 4 \\
18 & 100 & 0.009 & 0.329 & 0.000 & 0.037 & 0.006 & 0.020 & 0.001 & 0.022 & 4 & 4 \\
19 & 148 & 0.023 & 0.493 & 0.226 & 0.019 & 0.008 & 0.012 & 0.001 & 0.019 & 5 & 6 \\
20 & 130 & 0.007 & 0.346 & 0.000 & 0.025 & 0.007 & 0.016 & 0.001 & 0.024 & 5 & 6 \\
\hline
\end{tabular}

The experiments were carried out for two variants of each problem that differed in matrices $\mathbf{H}(d)$ and sets $J(p)$. The results are presented in Tables 10 and 11 where NO is the number of rows of a matrix $\mathbf{H}$ of possible orientations of all parts, TC is the calculation time in seconds, NV and NC are the numbers of variables and constraints in MIP formulations, respectively. $\mathbf{H}$ is built on the base of matrices $\mathbf{H}(d)$ and takes also into account constraints $D^{S S}$ and $D^{S M}$.

Table 10. The results for the first variant

\begin{tabular}{lllllll}
\hline Problem & NO & TC & $Q(P)$ & $m$ & NV & NC \\
\hline 1 & 20 & 10.9 & 158.5 & 4 & 3513 & 122608 \\
2 & 16 & 16.4 & 119.5 & 3 & 3188 & 72585 \\
3 & 10 & 14.4 & 143.5 & 4 & 3183 & 100419 \\
4 & 8 & 13.6 & 103 & 3 & 2858 & 56796 \\
5 & 125 & 10.6 & 136 & 4 & 3112 & 293550 \\
6 & 48 & 14.2 & 96.5 & 3 & 2772 & 206452 \\
7 & 100 & 16.9 & 159.5 & 4 & 4307 & 266213 \\
8 & 64 & 69.2 & 120.5 & 3 & 3977 & 153665 \\
9 & 50 & 24.8 & 144.5 & 4 & 3977 & 240794 \\
10 & 32 & 24.3 & 104 & 3 & 3647 & 137846 \\
11 & 40 & 20.2 & 159 & 4 & 4212 & 220392 \\
12 & 32 & 44.2 & 119.5 & 3 & 3887 & 119849 \\
13 & 40 & 40.1 & 148.5 & 4 & 3732 & 178124 \\
14 & 24 & 8.3 & 91 & 2 & 3402 & 103066 \\
15 & 200 & 29.2 & 160 & 4 & 5006 & 385227 \\
16 & 128 & 64.6 & 120.5 & 3 & 4676 & 200959 \\
17 & 200 & 25.2 & 160 & 4 & 4606 & 322529 \\
18 & 96 & 43.1 & 120 & 3 & 4271 & 173516 \\
19 & 1000 & 47.8 & 161 & 4 & 5422 & 536299 \\
20 & 384 & 76.6 & 121 & 3 & 5082 & 288161 \\
\hline & & & & & & \\
\end{tabular}


Table 11. The results for the second variant

\begin{tabular}{lllllll}
\hline Problem & NO & TC & $Q(P)$ & $m$ & NV & NC \\
\hline 1 & 45 & 48.8 & 147.5 & 4 & 3538 & 122093 \\
2 & 45 & 71.7 & 87 & 2 & 3218 & 72155 \\
3 & 27 & 95 & 138 & 4 & 3208 & 99944 \\
4 & 27 & 110.8 & 79.5 & 2 & 2888 & 56406 \\
5 & 405 & 128.6 & 133.5 & 4 & 3152 & 293090 \\
6 & 405 & 45.8 & 75.5 & 2 & 2832 & 206092 \\
7 & 405 & 95.6 & 148 & 4 & 4352 & 265598 \\
8 & 405 & 350.2 & 87.5 & 2 & 4032 & 153140 \\
9 & 243 & 202.3 & 138.5 & 4 & 4022 & 240219 \\
10 & 243 & 534 & 80 & 2 & 3702 & 137361 \\
11 & 135 & 78.6 & 148 & 4 & 4242 & 219782 \\
12 & 135 & 75.9 & 87 & 2 & 3922 & 119324 \\
13 & 75 & 157.7 & 148 & 4 & 3742 & 177714 \\
14 & 75 & 33.1 & 91 & 2 & 3422 & 102746 \\
15 & 1215 & 167.1 & 148.5 & 4 & 5056 & 384517 \\
16 & 1215 & 398 & 87.5 & 2 & 4736 & 200339 \\
17 & 675 & 62.6 & 152.5 & 4 & 4636 & 321939 \\
18 & 675 & 104.5 & 91.5 & 2 & 4316 & 173021 \\
19 & 6075 & 645.4 & 153 & 4 & 5472 & 535609 \\
20 & 6075 & 1152.2 & 92 & 2 & 5152 & 287571 \\
\hline
\end{tabular}

The obtained results show that the tested industrial problems could be solved to optimality in reasonable time. However, the complexity of the problem and the time required to solve it strongly depends on the density of inclusion and exclusion constraints which in fine define the number of possible solutions.

\section{Conclusions}

In this paper, we developed a new mathematical model for the cost optimization problem in the design of machining flow lines composed of reconfigurable machines and used for batch production. This new model includes the definition of precedence, exclusion and inclusion constraints among operations and different types of equipment, such as machining modules, turrets, spindle boxes and workheads with single spindles. The configuration of the line is decided by optimizing the assignment of operations to the pieces of equipment while satisfying technical and technological constraints as well as the required final completion time.

The developed model is general and can be applied to different reconfigurable manufacturing systems (RMS) used in machining industry. The proposed model has been successfully validated on industrial case studies. The obtained results show that it can be used in practice for designing RMS for variable batches of parts required in low volume. In particular, the solution time for finding optimal solutions for industrial problems is acceptable. Therefore, the use of the developed model may help designers to evaluate quickly different design configurations and the investment costs required. Thus, the total cost and design time can be substantially reduced. The future research will include the integration of environmental factors into the considered problem. Despite of the fact that the investment cost is still 
important for decision makers in industry, solutions can be also compared on the basis of their environmental indicators such as energy consumption, waste generation, options available for the end of life treatment. However, an important effort will be needed to properly model these environmental indicators.

Acknowledgements : This work was partially supported by the region Pays de la Loire (France).

\section{References}

Abbasi M, Houshmand M. Production planning of reconfigurable manufacturing systems with stochastic demands using Tabu search. Int J Manuf Technol Manage, 2009; 17(1-2):125-48.

Abbasi M, Houshmand D. Production planning and performance optimization of reconfigurable manufacturing systems using genetic algorithm. Int J Adv Manuf Technol, 2011; 54(1-4): 373-92.

Ashraf M, Hasan F. Configuration selection for a reconfigurable manufacturing flow line involving part production with operation constraints. Int J Adv Manuf Technol, 2018; 98(5-8), 2137-56.

Andresen AL, Brunoe TD, Nielsen K. Reconfigurable manufacturing on multiple levels: literature review and research directions. In: Advances in Production Management Systems: Innovative Production Management towards Sustainable Growth. IFIP conference; Springer; 2015. pp. 266-273.

Andersen AL, Nielsen K, Brunoe TD. Prerequisites and barriers for the development of reconfigurable manufacturing systems for high speed ramp-up. Procedia CIRP, 2016; 51: 7-12.

Andersen AL, Brunoe TD, Nielsen K, Rosio C. Towards a generic design method for reconfigurable manufacturing systems: analysis and synthesis of current design methods and evaluation of supportive tools. J Manuf Syst, 2017; 42: 179-95.

Battaïa O., Dolgui A., Guschinsky N. Decision support for design of reconfigurable rotary machining systems for family part production. Int J Prod Res, 2017; 55(5): 1368-1385.

Bensmaine A, Dahane M, Benyoucef L. A non-dominated sorting genetic algorithm based approach for optimal machines selection in reconfigurable manufacturing environment. Comput Ind Eng, 2013; 66(3): 519-24.

Bortolini M, Galizia FG, Mora C. Reconfigurable manufacturing systems: Literature review and research trend. J Manuf Syst, 2018; 49: 93-106.

Brahimi N, Dolgui A, Gurevsky E, Yelles-Chaouche AR. A literature review of optimization problems for reconfigurable manufacturing systems. IFAC PapersOnline, 2019. to appear

Buer S-V, Strandhagen JO, Chan FTS. The link between Industry 4.0 and lean manufacturing: mapping current research and establishing a research agenda. Int J Prod Res, 2018; 56(8): 2924-40.

Dolgui A, Levin G, Rozin B. Optimisation of the aggregation and execution rates for intersecting operation sets: an example of machining process design. Int J Prod Res, 2019; doi.org/10.1080/00207543.2019.1629668

Dou JP, Dai XZ, Meng ZD. Configuration selection of reconfigurable manufacturing system based on hybrid analytical hierarchy process. Comput Integr Manuf Syst, 2007; 13(7): 1360-66.

Dou JP, Dai XZ, Meng ZD. Optimisation for multi-part flow-line configuration of reconfigurable manufacturing systems using GA. Int J Prod Res, 2010; 48(14): 4071-100.

Dou J, Li J, Su C. Bi-objective optimization of integrating configuration generation and scheduling for reconfigurable flow lines using NSGA-II. Int J Adv Manuf Technol, 2016; 86(5-8): 1945-62. 
Farid AM. Measures of reconfigurability and its key characteristics in intelligent manufacturing systems. J Intell Manuf, 2017; 28 (2), 353-369.

Goyal KK, Jain PK, Jain M. Optimal configuration selection for reconfigurable manufacturing system using NSGA II and TOPSIS. Int J Prod Res, 2012; 50(15): 4175-91.

Goyal KK, Jain PK, Jain M. A novel methodology to measure the responsiveness of RMTs in reconfigurable manufacturing system. J Manuf Syst, 2013; 32(4): 724-30.

Haddou-Benderbal H, Dahane M, Benyoucef L. Flexibility-based multi-objective approach for machine selection in reconfigurable manufacturing system (RMS) design under unavailability constraints. Int $\mathrm{J}$ Prod Res, 2017; 55(20): 6033-51.

Huettemann G, Gaffry C, Schmitt RH. Adaptation of reconfigurable manufacturing systems for industrial assembly_review of flexibility paradigms, concepts and outlook. Procedia CIRP, 2015; 52: 112-7.

Koren Y, Heisel U, Jovane F, Moriwaki T, Pritschow G, Ulsoy G, et al. Reconfigurable manufacturing systems. CIRP annals - manufacturing technology, 1999; 48(2): 527-40.

Koren Y, Shpitalni M. Design of reconfigurable manufacturing systems. J Manuf Syst, 2010; 29(4): 13041.

Koren Y, Wang W, Gu X. Value creation through design for scalability of reconfigurable manufacturing systems. Int J Prod Res, 2017; 55(5): 1227-1242.

Liao Y, Deschamps F, de Freitas Rocha Loures R, Pierin Ramos L.F. Past, present and future of Industry 4.0 - a systematic literature review and research agenda proposal. Int J Prod Res, 2017; 55(12): 3609-29.

Moghaddam, S., Houshmand, M., and Valilai, O. Configuration design in scalable reconfigurable manufacturing systems (RMS) a case of single-product flow line (SPFL). Int J Prod Res, 2017; 56(11), 3932-54.

Renzi C, Leali F, Cavazzuti M, Andrisano AO. A review on artificial intelligence applications to the optimal design of dedicated and reconfigurable manufacturing systems. Int J Adv Manuf Technol, 2014; 72(1-4): 403-418.

Rosio C, Safsten K. Reconfigurable production system design-theoretical and practical challenges. J Manuf Technol Mngmt, 2013; 24(7): 998-1018.

Saxena LK, Jain PK. A model and optimisation approach for reconfigurable manufacturing system configuration design. Int J Prod Res, 2012; 50(12): 3359-81.

Singh A, Gupta S, Asjad M, Gupta P. Reconfigurable manufacturing systems: journey and the road ahead. Int J Syst Assur Eng Mngmt, 2017; 8(2): 1849-1857.

Son SY, Lennon Olsen T, Yip-Hoi D. An approach to scalability and line balancing for reconfigurable manufacturing systems. Integr Manuf Syst, 2001; 12(7): 500-11.

Spicer P, Yip-Hoi D, Koren Y. Scalable reconfigurable equipment design principles. Int J Prod Res, 2005; 43(22): 4839-52.

Wang W, Koren Y. Scalability planning for reconfigurable manufacturing systems. J Manuf Syst, 2012; 31(2): 83-91.

Xiaobo Z, Jiancai W, Zhenbi L. A stochastic model of a reconfigurable manufacturing system. Part 1: a framework. Int J Prod Res, 2000; 38(10): 2273-85.

Xiaobo Z, Wang J, Luo Z. A stochastic model of a reconfigurable manufacturing system. Part 2: optimal configurations. Int J Prod Res, 2000; 38(12): 2829-42.

Xiaobo Z, Wang J, Luo Z. A stochastic model of a reconfigurable manufacturing system. Part 3: optimal selection policy. Int J Prod Res, 2001; 39(4): 747-58. 
Xiaobo Z, Wang J, Luo Z. A stochastic model of a reconfigurable manufacturing system. Part 4: performance measure. Int J Prod Res, 2001; 39(6): 1113-26.

Xu LD, Xu EL, Li L. Industry 4.0: state of the art and future trends. Int J Prod Res, 2018; 56(8): 2941-62.

Yin Y, Stecke KE, Li D. The evolution of production systems from Industry 2.0 through Industry 4.0. Int J Prod Res, 2018; 56(1-2): 848-861.

Youssef AM, ElMaraghy HA. Modelling and optimization of multiple-aspect RMS configurations. Int J Prod Res, 2006; 46(22): 4929-58.

Youssef AM, ElMaraghy HA. Optimal configuration selection for reconfigurable manufacturing systems. Int J Flex Manuf Syst, 2007; 19(2): 67-106.

Youssef AM, ElMaraghy HA. Availability consideration in the optimal selection of multiple-aspect RMS configurations. Int J Prod Res, 2008; 46(21): 5849-82. 